\title{
THE EFFECT OF SAND-SPECIFIC EXERCISES IN DEVELOPING SOME PHYSICAL AND SKILL CAPABILITIES OF YOUNG FOOTBALL PLAYERS BETWEEN THE AGES OF 17-19 YEARS
}

\author{
Ahmed Abdul aziz Faraj, Prof.Dr. Firas Mutasher Abdul Reda \\ University of Baghdad / College of Physical Education and Sports Sciences
}

DOI: $10.37648 / \mathrm{ijrssh} . v 10 \mathrm{i02} .040$

Received: 20 $0^{\text {th }}$ March, 2020; Accepted: $24^{\text {th }}$ April, 2020; Published: $13^{\text {th }}$ May, 2020

\begin{abstract}
Football is one of the team sports that was positively affected by the development of science related to the sports field and the development of methods and methods of preparing the players physically and technically, which helped the players to raise the level of performance and achieve excellence and sports achievement and One of the objectives of the research Preparing exercises using the Raml field for young footballers and The researcher used the experimental approach that is based on And by the experimental design method with two experimental and controlling equivalents and The two researchers were inferred - The use of training on sandy ground contributed positively to the development of physical and skill capabilities of young football players.
\end{abstract}

\section{INTRODUCTION}

Football is one of the team sports that was positively affected by the development of science related to the sports field and the development of methods and methods of preparing the players physically and technically, which helped the players to raise the level of performance and achieve excellence and sports achievement.

And finding the most appropriate training methods in football is an important requirement for the development of players in the physical, skill and planning aspects. For this reason, researchers in the field of physical education have devoted to developing advanced training methods so that they may achieve positive effects, and from these exercises is training using a sandy medium that constitutes resistance Against the inner force. As increasing sand resistance increases and improves the player's level in the physical and functional aspects, as it shows its real importance in improving the imbalance between the different muscle groups.

As is well known, the resistance shown by the player on the sand is one of the training methods that can develop physical capabilities through the use of exercises that are directly related to athletic performance.

Football is one of the team sports that accompanied this development in all aspects of physical, skill and planning, and this is what we see in the World Cup soccer tournaments in terms of the novelty of playing methods, and this results from the use of several methods in the physical, skill and advanced planning preparation. 
Football is a sport that requires speed in performance, accuracy and change in tempo, and this is what distinguishes it from other sports. As you need high performance requirements for the purpose of achieving high achievement, as football has different skills that require consistency and arrangement in training between those skills on the one hand and physical capabilities on the other hand. And must be characterized by modern training overlapping between skills and capabilities so that they serve each other.

And at the present time, a recent trend has appeared in the training of soccer players, as we see in Arab and international clubs performing their training on the sandy beach after eight minutes of warm-up and running training. One of the characteristics of sand training is making body weight resistance

The man is heavier in sand, which gives more resistance to the body, as movement on sand is heavier than movement on other surfaces such as dry land, tartan, wood, or heavy.

When moving the legs on the sand, it corresponds to a large resistance, this resistance can be used to strengthen the muscles and increase the range of motion in the joint and when the speed of their movement increases the resistance to them increases, and this training is characterized by difficulty and gaining more strength. Also, increasing sand resistance increases and improves the level of the player from the physical side and its impact on the skill aspects of football players. One of these skill aspects is the development of complex skills in football as they represent models of different forms of a set of individual skills that merge with each other and overlap in their final stages to form The beginning of the next skill, which the player performs in a specific playing position to achieve a specific goal according to his requirements.

From the above, the importance of research lies:

- This study is an organized scientific attempt to raise the level of physical and skill capabilities of young soccer players in the governorate of Baghdad, through the use of exercises on sand as a different and variable medium in training that depends on providing a new scientific method in the training process for coaches and soccer players on sandy fields.

- The applied importance of this study lies in assisting and benefiting the trainers from the study results in using sand training as a type of training to contribute to developing the physical and skill capabilities of the players when they train in conditions where the external resistances increase in order to raise the physical and skill level for them.

Research problem

The idea of training on sandy ground came as one of the resistance exercises, as its importance appears through the difficulty of movement on the sandy ground, which is produced due to the increase in the relative movement between dry sand grains that are not coherent, which forces the player to exert more strength and effort to overcome this difficulty in movement, and lies This is important in determining the coefficient of friction that is less on sandy (ground) surfaces compared to grassy (ground) surfaces, which in turn requires a double effort from the player to overcome this resistance.

Therefore, the researcher decided to prepare special exercises for young soccer players, ages (17-19 years), using sandy land for training, due to the lack of their use in training youth teams in Iraq and studying their impact on developing some physical and skill capabilities.

Research Objectives

.Preparing exercises using the Raml field for young footballers -

- Knowing the effect of sandy exercises on developing some physical and skill capabilities of young football players.

- Identify the differences between the experimental and control groups in the post-tests of research variables.

Research hypotheses

- There are statistically significant differences between the pre and post tests for some physical and skill capabilities of the experimental and control groups and for the benefit of the post tests.

- There are statistically significant differences in the dimensional tests of some physical and skill capabilities between the experimental and control groups and in favor of the experimental group.

Research Areas

- The human sphere: Al-Jaish Sports Club players, the youth age group (under 19 years).

Timeline: For the period from (7/6/2019) to (14/14/2019). -

- Spatial domain: Al-Jaish Sports Club (Al-Remal Stadium) Baghdad / Al-Zafaraniya. 


\section{MATERIALS AND METHODS:}

\section{Research Methodology:}

The researcher used the experimental approach that is based on "an approved and controlled change to the specific conditions of an event, and observing the changes resulting from the event itself and its interpretation." And by the experimental design method with two experimental and controlling equivalents.

\section{Search community and sample:}

The research sample is one of the necessities of scientific research, as the researcher must choose the research sample so that this sample accurately represents the indigenous community, so the sample means "the way of collecting data and information from and about the elements and specific cases that are chosen by a group of elements with a specific group of elements To achieve the aims of the study.

The research community included the young players aged (17-19) years for the Army Football Club for the year 2019-2020, whose number is (24) players and who are officially registered within the lists of the Iraqi Central Football Association, chosen in an intentional manner, and after excluding the goalkeepers, who are (2) Two players. And the selection of (4) players as an exploratory experiment, the rest was distributed into two experimental and control groups, each group consisting of (9) players and in a random and regular manner (the lottery). And by (75\%) of the research community.

\section{homogeneity of the sample}

In order to reach one level of the research sample and to avoid the variables that affect the research results. The researcher performed homogenization on his research sample by taking the variables (age, body mass, height, training age)

The homogeneity of the research sample in the indicators of growth and training

\begin{tabular}{|l|l|l|l|l|l||l|}
\hline $\begin{array}{l}\text { Coefficient } \\
\text { of torsion }\end{array}$ & Mediator & $\begin{array}{l}\text { standard } \\
\text { deviation }\end{array}$ & $\begin{array}{l}\text { Arithmetic } \\
\text { mean }\end{array}$ & $\begin{array}{l}\text { measruing } \\
\text { unit }\end{array}$ & Variables & sequence \\
\hline \hline 0.156 & 216.500 & 6.449 & 216.125 & Months & Age & 1 \\
\hline \hline 0.156 & 68.000 & 3.256 & 67.750 & Kg & body mass & 2 \\
\hline \hline 0.000 & 173.000 & 3.810 & 172.625 & Centimeters & Length & 3 \\
\hline \hline 0.845 & 8.000 & 0.806 & 7.375 & the year & Training age & 4 \\
\hline
\end{tabular}

Means of gathering information, tools and devices used in research:

Means of collecting information

. Arab and foreign sources and the Internet -

. Tests and measurements -

. - Questionnaires to obtain expert opinion to determine the physical capabilities and basic skills of football and their appropriate tests for the research sample.

- Data registration form for physical abilities and basic skills used in the research.

.Devices and tools used for research -

. - A soccer field

Dimensional sand playground (20 x $20 \mathrm{~m})$. -
Sony camera (1), with DVD (2) -

. A tape measure -

Electronic stopwatch -

(10) .soccer balls -

-- Burke Square Planning

A medical scale for measuring ma -

Type Whistle (AGME). -

- Type HP laptop (1).

Field research procedures:

Define search variables

The researcher carried out a set of research procedures to carry out a research in the appropriate way to achieve his goal through the following: 
.Preparing a sand playground -

.Determining the physical capabilities under consideration -

.Defining the basic skills under discussion for young football players -

.Defining the tests related to physical abilities and basic skills -

.Preparing a suitable atmosphere for conducting the tests -

- Conducting the exploratory experiment on a sample similar to the research sample.

.Apply the tests to the research sample -

.The researcher prepared a form for unloading and tabulating data -

sand pitch specifications

Dimensions of the stadium: The stadium's measurements were with dimensions of $(30 \times 20)$ meters, with an area of (600 square meters), with a depth of sand $(60 \mathrm{~cm})$, and a safety distance ( 2 meters from all sides of the stadium). Its specifications: Persons with a height of (1 meter) were placed in the corners of the stadium, and a colored tape was placed solutions to the perimeter of the stadium, to show its limits for the players, and a goal with dimensions ( 2 m height x 3 m width) number (2).

Sand characteristics: The quality of sand was from the sand of the beaches of the Tigris River, so that it was pebble-free and of a thickness $(60 \mathrm{~cm})$.

Defining variables of physical abilities

One of the important practical steps in scientific research related to sports and sporting activities is to define the research variables and their tests, after the researcher has learned about some available sources as well as using the international information network (the Internet) and consulted with the supervisor to determine some physical capabilities that are appropriate for this study, where the researcher settled on The following physical abilities as major axes of the level of basic football performance and the proposed physical abilities for the research are:

.- Explosive force

.The force marked with speed -

.Withstand strength -

.Withstand speed -

:Defining skill performance variables

Through the researcher's observations and field experience, and through personal interviews with specialists and consultation with the supervisor, the most important basic skills have been identified that can be affected by the rise or fall of special strength and the special endurance of football players under the age of (19) years during skill performance.

The main skills proposed are: (scoring, handling, rolling)

specifications for physical tests

Test run 180 meters. -

Objective: to measure velocity.

Instruments: stopwatch, four characters, distance between one person and 15 meters.

Performance description: After giving the starting signal, the laboratory will move from the first person (the beginning) to the second person and return to the beginning and run towards the third person and return to the beginning, then run towards the fourth person and return to the beginning. In this the laboratory will have completed the test for a distance of $180 \mathrm{~m}$.

Recording: The time is recorded in seconds and for the nearest $1 / 100$ of a second.

Continuous feet test together to travel the largest distance per minute:

The goal of the test: to measure the force intensity.

Tools: Stop watch, two lines drawn for start and end

Performance description: The laboratory stands behind the starting line and upon hearing the starting signal the laboratory continuously records the feet together for a minute.

Registration: records the distance the laboratory has traveled from the starting line to the end of the prescribed time period.

- Explosive force test

Test name: vertical jump

Purpose of the test: the explosive strength of the two men.

The tools used: a smooth wall with numbers starting from (150) $\mathrm{cm}$ up Burke -

- Performing the test: He touches the fingers of his hand in the bork and then stands so that one of his arms is next to the wall and raises his distinctive arm along its entire stretch to make a mark with the fingers on the wall. It should be noted that he should not raise the heels from the ground. With the knees bent half and then swinged forward high for the jump to the farthest distance you can reach to make another mark with the distinct finger of the hand and it is in its full extent.

Registration: The number in which the mark was placed is recorded. The distance between the first and the second 
mark expresses the amount of explosive power in the laboratory compared to the centimeters.

Distinguished strength test with speed:

Name of the test: Partridge on one leg for a distance of $(30 \mathrm{~m})$ right - left. -

- The goal of the test: to measure the force marked by the velocity of the calf muscles.

.The tools used -

. stopwatch -

. tape measure -

Watcher watching the player -

A striped square with a start and end lines -

$\checkmark$ Performance description

- The player stands touching the starting line with the jump leg and the free leg back.

- Upon hearing the starting signal, the player launches with the part (jumping) on one leg to the end of the line set for a distance of $(30 \mathrm{~m})$.

:Registration method

- The time taken for the least part of a second is calculated from the starting line to the finish line and according to the test conditions.

\section{Skill Test Specifications}

The first test

- Rolling ball run test between (5) characters

The goal of the test: to measure the skill of rolling.

Description of performance: The first person is placed

2,70 meters away, i.e. (9) feet from the starting line

The player stands with the ball behind the starting line, and when the starting signal is given, the player runs the ball between the sides back and forth.

Each player is given two consecutive attempts.

Time counts $1 / 10$ of a second.

Player's score is the average total time the player takes to perform the two attempts.

The second test

Test name: - Scoring on overlapping rectangles.

The goal of the test: - To measure the accuracy of near scoring.

The equipment used: - A soccer ball (3) a distance (9) feet from the middle of the starting line, an electronic stopwatch.

Test procedures:

Four rectangular targets on a smooth wall perpendicular to the ground paint their dimensions as follows:

The first rectangle is $2 \times 6$ feet

The second rectangle is $4 \times 12$ feet
The third rectangle is $6 \times 18$ feet

Fourth rectangle $8 \times 24$ feet

A line parallel to the wall is drawn a distance of (20) feet from the goal, the player stands with the ball behind the starting line and when the starting signal is given the player kicks the ball with one of his feet towards the wall trying to target it towards the small goal $(2 \times 6$ feet $)$ the most number of times during the time scheduled for the test It is (30) seconds

Registration method:

The first rectangle is 4 degrees

The second rectangle is 3 degrees

The third rectangle has two steps

The fourth rectangle is one degree

Zero when the ball does not touch any of the rectangles.

Directions:

.It is allowed to kick the ball with either foot -

- The player is not allowed to kick the ball towards the goal except after returning to the starting line.

The third test

Handling test towards a small target 20 meters away

Objective of the test: to measure the accuracy of handling

The tools used: (5) footballs, and a small goal $(110 \mathrm{~cm} \mathrm{x}$ $63 \mathrm{~cm}$ )

Test Procedures: Draw a line with a length of $(1 \mathrm{~m})$ at a distance $(20 \mathrm{~m})$ from the small target, and place a fixed ball on the starting line as shown in Figure (1)

Test description: The player stands behind the starting line facing the small target, and begins when the signal is given by handling the ball towards the target to enter it, and each player (5) is given five consecutive attempts.

Score: The score is calculated by the total score obtained by the player from handling the five balls, as follows:

.Two scores for each correct attempt that enters the small goal -

.One degree if the ball hit the post or cross and did not enter the goal -

.Zero if the ball is outside the small goal-

\section{Exploration Experience}

The researcher conducted the first exploratory experiment on 12/26/2018 and the second exploratory experiment on 3/2/2019 on the 4-man poll sample from Al-Jaish Sports Club with the presence of the assistant work team:

The first exploratory experiment targeted:

. The suitability of special exercises with the research sample - 
. Fit the exercises with the time of the specified training units -

. Knowing the difficulties facing the sample during application -

As for the second exploratory experience, it targeted:

- Knowing the suitability of the tests for the sample and knowing the time taken for the test.

- Ensuring the efficiency of the assistant team and the accuracy in carrying out the tests.

. Verifying the validity of the devices and tools used -

\section{Main experience}

Special exercises on sandy lands

In order to follow the proper scientific context to reach the most accurate results to solve the research problem and in order to achieve the goals of the research, the researcher developed a set of special exercises in order to develop some physical capabilities and some basic skills in football. The researcher applied these exercises during the special preparation period to a sample of football players They represent the youth of the Army Club, and the researcher relied on his personal experience as a former player, as well as on the experience of the supervisor, in addition to his briefing on references, sources and studies related to football.

The researcher approved the application of special exercises for the experimental group in the main section of the training unit, and the researcher did not interfere in the curriculum used by the trainer with respect to the control group and these exercises were given for a period of (10) weeks and at the rate of (3) training units per week and a total of (30) training units During the special preparation period for the team.

The researcher prepared a set of special exercises according to the following.

- Taking into account the principle of diversity in performing exercises within the training unit so that players do not feel bored and monotonous.

Follow the principle of progression from easy to difficult and simple to complex.

Implementing the research experiment

Starting the implementation of units using exercises, so the first training unit was on Friday 7/6/2019, and the last training unit was on Wednesday 14/8/2019 for the members of the experimental group by three training units per week (Friday, Monday, Wednesday) and the - The percentage of development : number of training units reached (30) A unit and the time of each training unit (90 minutes) was divided into three sections:

. - The introductory section 20 minutes

. Section for main 60 minutes -

. - Closing section 10 minutes

The work of the researcher is limited to the educational and applied parts only of the main section of the training unit, time (60 minutes) and allocated (15d) to the educational part and (45d) to the applied part. Tables ( 9 , 10) show the time distribution of the exercises

As for the control group: the same exercises are used but on the grassland.

The researcher calculated the partial stresses of special exercises by the maximum frequency of each exercise $x$ the required intensity / 100, and the researcher tightly controlled the training units by increasing the size and fixing the rest periods or raising the size and reducing the rest periods. The researcher used the method of low and high intensity training in his own exercises In line with the nature of the variables and the research sample. Physical and skill exercises aim to develop the physical capabilities and basic skills under consideration.

after-test

After completing the application of special exercises on the research sample, the dimensional measurements of the research groups (the experimental group and the control group) were taken into account, "taking into account all the circumstances, the method of implementation and the tools used, as the two dimensional tests on Monday 19/8/2019 for both physical capabilities and basic skills in the grass field Of the club.

\section{Statistical means}

The researcher used the statistical bag SPSS (1) to process the data he obtained and from the statistical methods that he adopted:

. Arithmetic mean -

. The mediator -

. Standard deviation -

.Sprains are twisting -

.Kay Square -

.Test (t) for correlated and unrelated samples - 


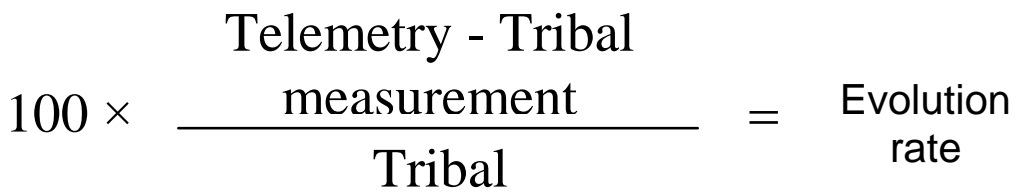

\section{RESULT AND DISCUSSION:}

\section{measurement}

The results of the post-tests of physical abilities between the experimental and experimental groups are presented, analyzed and discussed:

Table (1)

Shows the arithmetic mean, standard deviations, calculated and tabulated $(\mathrm{T})$ value and the significance of the differences between the two dimensional tests of the experimental and control groups for some physical capabilities of the research sample

\begin{tabular}{|c|c|c|c|c|c|c|}
\hline \multirow{2}{*}{$\begin{array}{l}\text { Statistical } \\
\text { significance }\end{array}$} & \multirow{2}{*}{$\begin{array}{l}\text { Calculated } \\
\text { value of }(\mathrm{t})\end{array}$} & \multicolumn{2}{|c|}{ Control group } & \multicolumn{2}{|c|}{ Experimental group } & \multirow{2}{*}{$\begin{array}{l}\text { Statistical } \\
\text { Parameters } \\
\text { Variables }\end{array}$} \\
\hline & & $\begin{array}{l}\text { standard } \\
\text { deviation }\end{array}$ & $\begin{array}{l}\text { Arithmetic } \\
\text { mean }\end{array}$ & $\begin{array}{l}\text { standard } \\
\text { deviation }\end{array}$ & $\begin{array}{l}\text { Arithmetic } \\
\text { mean }\end{array}$ & \\
\hline moral & 3.051 & 3.808 & 38.667 & 2.000 & 44.000 & $\begin{array}{l}\text { The explosive strength of the } \\
\text { feet }\end{array}$ \\
\hline moral & 5.275 & 1.253 & 13 & 0.941 & 11.445 & $\begin{array}{l}\text { Distinguished strength by the } \\
\text { speed of the feet }\end{array}$ \\
\hline moral & 7.668 & 1.563 & 37.222 & 2.818 & 44.222 & Exercise power \\
\hline moral & 2.334 & 2.421 & 37.889 & 1.302 & 35.222 & Speed up \\
\hline
\end{tabular}

Table (2)

It shows the difference between training physical abilities on sandy lands and regular training in the development ratios of the experimental and control groups

\begin{tabular}{|l|l|l|l|l|}
\hline $\begin{array}{l}\text { Evolution in } \\
\text { favor of the } \\
\text { group }\end{array}$ & $\begin{array}{l}\text { The difference } \\
\text { between the } \\
\text { percentages of } \\
\text { development } \\
\text { between the } \\
\text { two groups }\end{array}$ & $\begin{array}{l}\text { The rate of } \\
\text { development } \\
\text { of the control } \\
\text { group }\end{array}$ & $\begin{array}{l}\text { The evolution } \\
\text { rate of the } \\
\text { experimental } \\
\text { group }\end{array}$ & Physical abilities \\
\hline Experimental & $17.5 \%$ & $12.3 \%$ & $29.8 \%$ & The explosive strength of the feet \\
\hline Experimental & $18.9 \%$ & $18.2 \%$ & $37.1 \%$ & $\begin{array}{l}\text { Distinguished strength by the speed } \\
\text { of the feet }\end{array}$ \\
\hline Experimental & $19.1 \%$ & $3.4 \%$ & $22.5 \%$ & Exercise power \\
\hline Experimental & $6 \%$ & $13 \%$ & $19 \%$ & Speed up \\
\hline
\end{tabular}




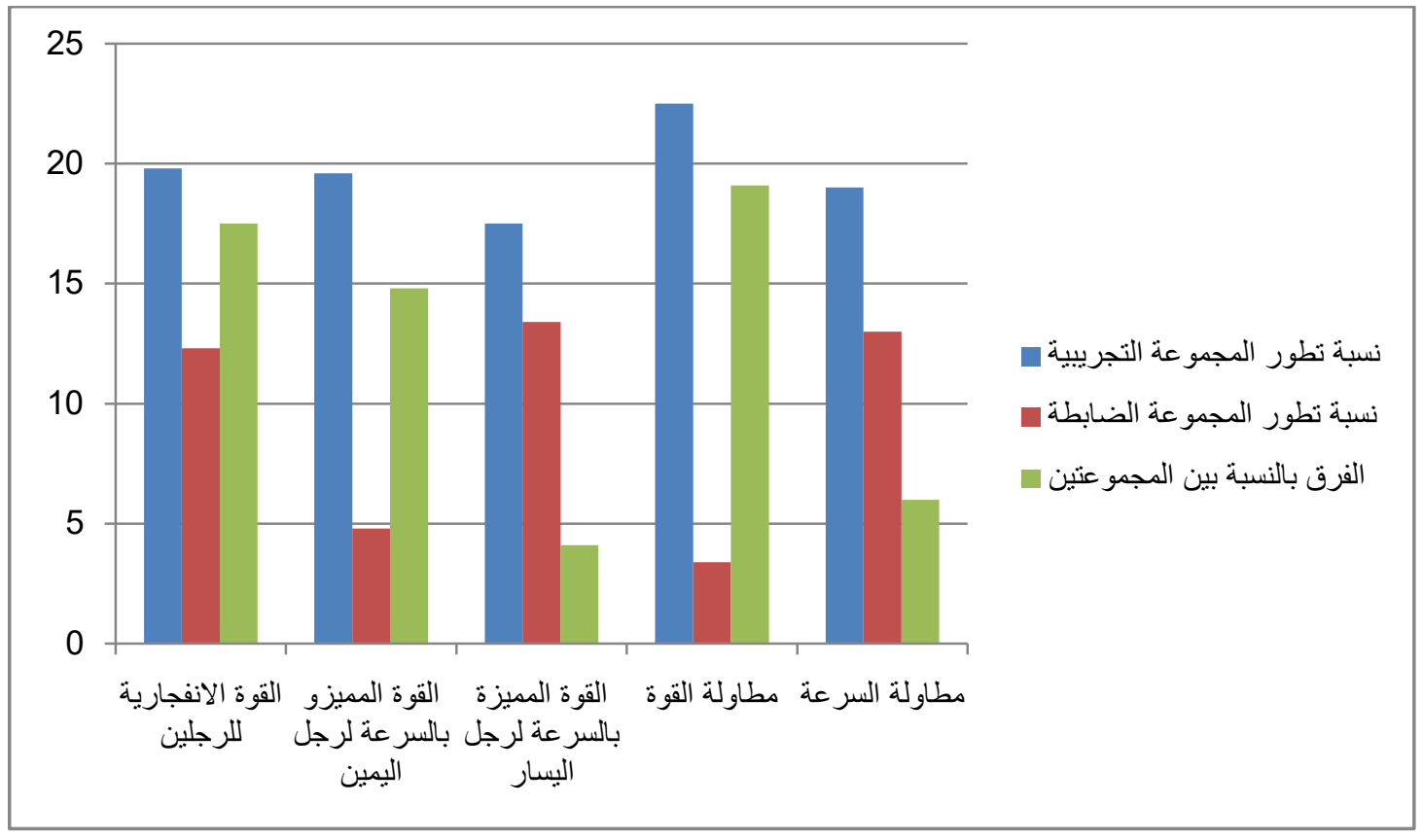

Figure (1) shows the percentage of development of the experimental and control groups and the difference between the two groups in the percentage of development in physical abilities

The results of Table (1) showed the arithmetic mean, the standard deviations, and the calculated value of $(\mathrm{T})$ between the experimental and experimental groups with the dimensional tests, in the tests of the explosive strength (vertical jump up) of (3.051), and the force distinguished by the speed (the partition on one leg (right leg) reached) 2.874), (Partridge on one leg (left leg)) reached (2.401), length of force (continuous partition of feet to travel the largest distance per minute) was 7.668, and speed length (ran $180 \mathrm{~m}$ apostate) reached (2.334), which is greater than value (C) The tables reached (2.12) in front of the degree of freedom (16) and at the level of significance $=(0.05)$. This indicates that the differences are significant and for all tests and For the benefit of the experimental group.

As for Table (2) and Figure (1), it showed differences in the rates of development between the two groups in the pre- and post-tests for the experimental group.

The researcher attributes the reasons for these differences to the physical capabilities under study due to the effectiveness of the exercises used on sandy and prepared lands according to the scientific foundations taking into account the intensity of the exercise and the periods of intercourse in a manner consistent with the capabilities and capabilities of the members of the experimental group, which confirms the validity of planning for these exercises used in the curriculum to achieve its goals and duties set For his sake, training in football must be characterized by planning, organizing and continuing on scientific grounds, with which he ensures the positive impact on the player's level and his continued progress in various aspects of football, such as the principle of gradual height in pregnancy and The correct timing for its recurrence "

And since the preparation process for young soccer players must take the holistic side in all its aspects because those aspects will depend on the construction of some of them on the construction of others and that any defect or deficiency of this process will negatively affect the rest of the aspects "without very high levels of physical characteristics (fitness elements) Physical) It will be difficult to achieve the goals of developing an efficient skill performance.

The exercise of physical and skill exercises on sandy soil requires more effort on the muscles due to the lack of cohesion of the sand grains, which requires players to exert more effort to overcome the resistance resulting from the incoherence of the sand grains, and this works by influencing 
On the muscles working with skill. This is indicated by (Osama Riyad, 2001) that "the muscle strength can be increased, developed and upgraded by increasing the resistance to the working muscle." In addition to that the training program includes practice exercises that work to delay fatigue by committing to carrying out exercises in the training units. "As training and commitment in the regular training program has the greatest impact in developing the elements of fitness, especially endurance (exercise), and this applies to all group and individual sports alike."

Present the results of the dimensional tests of the basic skills of the experimental and control groups, and analyze and discuss them:

Table (3)

Shows the arithmetic mean, the standard deviations, the calculated value of $(\mathrm{T})$ and the significance level for the dimensional tests of the experimental and control groups in the basic skills

\begin{tabular}{|l|l|l|l|l|l|l|}
\hline $\begin{array}{l}\text { Statistical } \\
\text { significance }\end{array}$ & $\begin{array}{l}\text { Calculated } \\
\text { value of (t) }\end{array}$ & \multicolumn{2}{|l|}{ Control group } & \multicolumn{2}{l|}{ Experimental group } & $\begin{array}{l}\text { Statistical } \\
\text { Parameters }\end{array}$ \\
\cline { 3 - 7 } & & $\begin{array}{l}\text { standard } \\
\text { deviation } \\
\text { moral }\end{array}$ & $\begin{array}{l}\text { Arithmetic } \\
\text { mean }\end{array}$ & $\begin{array}{l}\text { standard } \\
\text { deviation }\end{array}$ & $\begin{array}{l}\text { Arithmetic } \\
\text { mean }\end{array}$ & Variables \\
\hline moral & 2.475 & 1.269 & 12.111 & 1.269 & 10.889 & Accuragy of scoring \\
\hline moral & 3.500 & 0.782 & 7.111 & 0.527 & 6.444 & Handling \\
\hline & 2.309 & 0,707 & 9.667 & 0.527 & 10.444 & Rolling \\
\hline
\end{tabular}

Morale at the significance level $=(0.05)$ and with a degree of freedom $(16)$, Table $(\mathrm{T})$ value $=(2.12)$

The results of Table (3) showed the arithmetic mean, the standard deviations, and the value of (T) calculated between the dimensional tests of the control and experimental groups, and the scoring accuracy tests (scoring on a divided goal) amounted to (2.774), and the handling (accuracy of passing the ball on a small goal) amounted to $(3,500)$ It reached $(2.309)$, which is greater than the value of the tabular $(\mathrm{T})$ of $(2.12)$

In front of the degree of freedom (16) and at the significance level $=(0.05)$, this indicates that the differences are significant and in favor of the experimental group.

Table (4)

It shows the difference between basic skills training on sandy terrain and regular training in the development ratios of the experimental and control groups

\begin{tabular}{|l|l|l|l|l|}
\hline $\begin{array}{l}\text { Evolution in favor } \\
\text { of the group }\end{array}$ & $\begin{array}{l}\text { The difference } \\
\text { between the rate of } \\
\text { percentages of } \\
\text { development } \\
\text { between the two } \\
\text { groups }\end{array}$ & $\begin{array}{l}\text { The evolution rate } \\
\text { development of the } \\
\text { control group } \\
\text { of } \\
\text { experimental } \\
\text { group }\end{array}$ & basic skills \\
\hline Experimental & $16.98 \%$ & $37.35 \%$ & $33 \%$ & Scoring \\
\hline Experimental & $33.59 \%$ & $22.41 \%$ & $56 \%$ & Handling \\
\hline Experimental & $7.36 \%$ & $10.64 \%$ & $18 \%$ & Rolling \\
\hline
\end{tabular}


Table (4) showed a difference between the ratios between the two groups in favor of the experimental group

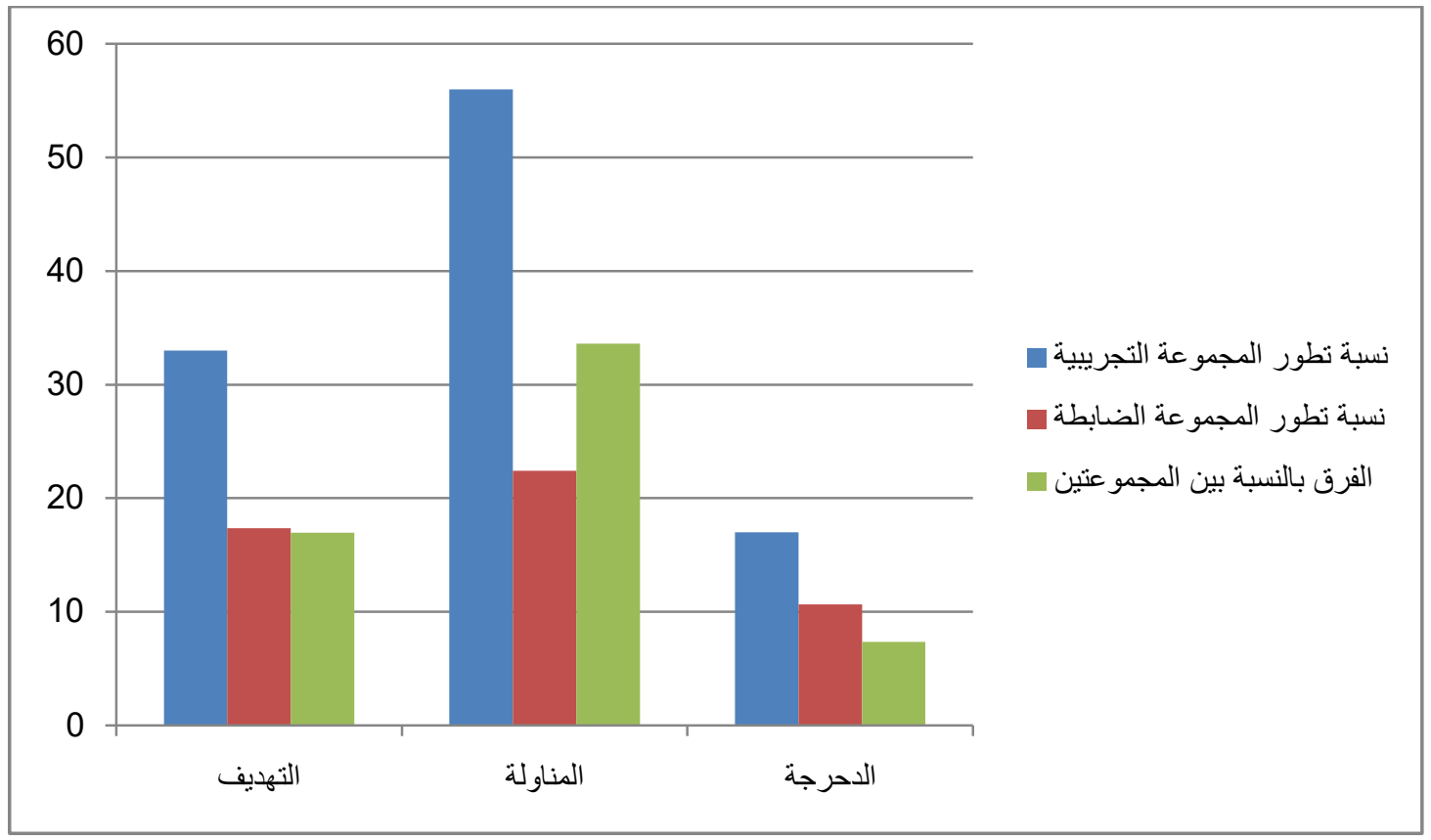

Figure (2): shows the percentage of development of the experimental and control groups, and the difference between the two groups in the percentage of development in the basic skills of football

The researcher attributes the reasons for these differences to the skills under study that the application of the contents of the training program on sandy lands was due to the friction set imposed by the nature and properties of sandy lands. Act and change directions about moving to play on the grassy field.

This is consistent with (Abu Al-Ella Ahmed AbdelFattah, 2003) "The sand resistance works to raise the level of improvement of the player from the physical, skill and functional side, which shows its true importance in the imbalance between the different muscle groups"

Also, "The goal of skill preparation is to acquire and master all the basic skills of the game, as good application of skills helps to perform with less effort and the player is not injured and in the game of football, the player cannot perform the skill performance in the required manner except through mastering the skill areas, which in turn affects The ability of the players, both plans and physical, to confirm this during training on the performance of the skill or give sufficient time to master it well

There is a correlation between physical abilities and skill levels, as physical abilities affect the upgrading of the skill level of different team games. This is confirmed by (Muhammad Hassan Allawi, 1994), "Every successful skill performance in any sporting activity is preceded by physical and physiological capabilities related to the individual's preparations, and these capabilities perform their functions coherently in a sequential pattern that ultimately contributes to achieving better skill performance."

\section{CONCLUSIONS:}

The researcher reached the following conclusions:

- The use of training on sandy ground contributed positively to the development of physical and skill capabilities of young football players.

- The continuation of training according to the exercises prepared by the researcher on the sandy ground has strengthened the increase of the efficiency of the nervous and muscular systems to control, adapt, and regulate the various operations that are appropriate for the skillful performance of young players.

- There are significant differences in physical abilities and basic skills tests between the pre and post tests of the control and experimental groups and in favor of the post test, with a good rate of development. 


\section{ENDORSEMENT:}

In light of the researcher's findings, he recommends the following:

- Guidance using exercises on sandy ground as one of the training methods that affect developing the physical and skill capabilities of young football players.
- Carrying out similar studies with the introduction of functional and psychological abilities and other basic skills in football and other sports and for various stages.

\section{REFERENCES:}

- Hassan El-Shafei and Susan Moussa: Principles of Scientific Research in Physical and Mathematical Education: (Alexandria, Menchafa Al-Maarif, 1995).

- Ribhi Mustafa Alayyan and Othman Muhammad Ghunaim: Methods and Methods of Theoretical Scientific Research and Application, 1st floor: (Amman, Dar Safaa for Publishing and Distribution), 2000.

- Qassem Hassan Hussein: The Comprehensive Physical Sports Encyclopedia, Amman, Dar Al-Fikr for Printing and Publishing, 1998.

- Qais Naji Abdul-Jabbar - Sabotisi Ahmed: Tests, Measurement, and Principles of Statistics in the Sports Field, University of Baghdad, 1984.

- Muhammad Sobhi Hassanein: Calendar and Measurement in Physical Education, 5th edition, Dar Al-Fikr Al-Arabi, Cairo 2001.

- Mowaffaq Asaad Mahmoud: Tests and Tactics in Football, Amman, Jordan: Dar Degla Publishers and Distributors, 2007.

- Hamzah Muhammad Dudeen: Advanced Statistical Analysis Using sps, 2nd edition, Amman, Dar Al Masirah for Publishing, Distribution and Printing, 2013. Muhammad Sobhi Hassanein and Hamdi Abdel-Moneim: The Scientific Bases of Volleyball, Methods of Measurement and Calendar, 1st Floor, Cairo: The Book Center Publishing 2002.

- Taha Ismail, and (others): Football between theory and practice (Dar Al-Fikr Al-Arabi, Cairo, 1989).

- Mufti Ibrahim Hammad: Modern Sports Training, Planning, Application and Leadership, 1st edition, (Cairo, Dar Al-Fikr Al-Arabi, 1998).

- Osama Riyad: Sports Medicine and Athletics, 1st edition: (Cairo, The Book Publishing Center, 2001).

- Abu Al-Ella Ahmed Abdel-Fattah: Physiology of Athletic Training (Cairo, Dar Al-Fikr Al-Arabi, 2003).

- Jones,A.M. The effect of Endurance training on parmeter of Aerobic fitness. Sports Medicine, Volume 27, Number 6, 2000. 